\title{
Microemulsion of babassu oil as a natural product to improve human immune system function
}

\author{
This article was published in the following Dove Press journal: \\ Drug Design, Development and Therapy \\ 16 December 2014 \\ Number of times this article has been viewed
}

\author{
Rafael Souza Pessoa' \\ Eduardo Luzia França',2 \\ Elton Brito Ribeiro' \\ Patrícia Kelly Dias Lanes' \\ Natalina Galdeano Abud \\ Chaud' \\ Lucélia Campelo \\ Albuquerque Moraes ${ }^{2}$ \\ Adenilda Cristina Honorio- \\ França ${ }^{1,2}$
}

'Post Graduate Program in Material Science, ${ }^{2}$ Institute of Biological and Health Science, Federal University of Mato Grosso, Barra do Garças, MT, Brazil
Correspondence: Adenilda Cristina Honorio-França

Institute of Biological and Health Science, Federal University of Mato Grosso, Rodovia BR 070, $\mathrm{Km} 5 \mathrm{~s} / \mathrm{n}^{\circ}$, Barra do Garças, MT, CEP 78600-000, Brazil

Tel +55 663 40 I 2 I I 2 I

Email denifran@terra.com.br
Background: The aim of this study was to develop and characterize a babassu oil microemulsion system and determine the effect of this microemulsion on the functional activity of phagocytes.

Methods: The microemulsion was formulated using distilled water, babassu as the oil phase component, Sorbitan monooleate-Span $80^{\circledR}$ (SP), Polysorbate 80-Tween $80^{\circledR}$ (TW), and 1-butanol (BT). Pseudoternary diagrams were prepared, and microemulsion diagram regions were preselected. Rheological characterization and preliminary and accelerated stability tests were performed. The effect of the microemulsion on the interactions between leukocytes and bacteria was determined by superoxide release, phagocytosis, and microbicidal activity.

Results: The developed formulation SP/TW/BT (4.2/4.8/1.0) was classified as oil/water, showed a Newtonian profile, and had linear viscosity. When we assessed the interaction of the microemulsion or babassu oil with phagocytes, we observed an increase in superoxide, phagocytosis, and microbicidal activity.

Conclusion: The babassu oil microemulsion system is an option for future applications, including for vaccine delivery systems. Babassu oil is a natural product, so is an alternative for future immunotherapy strategies, in particular for infectious diseases.

Keywords: vegetable oil, babassu, microemulsion, phagocytes, delivery systems

\section{Introduction}

The development of drug and vaccine delivery systems has increased in recent years. Many such products improve the treatment of disease or stimulate the immune system. ${ }^{1}$ The literature has demonstrated that microemulsions (MEs) are an interesting strategy for delivery of therapeutic molecules. ${ }^{2}$ MEs are homogeneous dispersions of oil and water; they are translucent and thermodynamically stable, are stabilized by an interfacial film composed of conjugated surfactant and cosurfactant, ${ }^{3}$ and exist as droplets with a diameter in the order of $100 \mathrm{~nm} .{ }^{4}$ The controlled-release characteristics of an emulsion are determined by factors such as oil phase viscosity, the oil-to-water phase ratio, and emulsion droplet size.

Interest in identifying the relationships between MEs as delivery systems, their adjuvant activity, and their regulation of immune responses is growing, but study results remain controversial. Many investigators are in agreement that the particles are crucial to their adjuvant activity. ${ }^{5}$ One factor that may affect the system is the material used to form the particles. To clarify the influence of the ME on adjuvant activity, the ME-induced immune responses must be compared. Conversely, medicinal plants and plant extracts still have great relevance because of the use of active substances, such as pharmaceutical materials, to obtain both drugs and adjuvants.

In Brazilian ethnobotany, babassu, which is a generic name given to palm oil belonging to the family Arecaceae (Palmae) and members of the genera Orbignya and Attalea. ${ }^{6}$ 
Studies demonstrate that babassu has analgesic and antiinflammatory biological properties. ${ }^{7}$ Studies performed with a plant-derived compound in which the highest concentration was of babassu extract, confirmed that this herb activates the functional mechanisms of human phagocytes ${ }^{8,9}$ and can activate the immune system when combined with a modifiedrelease system. ${ }^{10}$ Several studies have also demonstrated that babassu oil has anti-inflammatory activity ${ }^{11,12}$ and healing properties. ${ }^{6,11,13}$

The main product used by the population is the oil of the babassu fruit. Babassu oil has a white to slightly yellowish color and corresponds to $4 \%$ of the total fruit weight. Babassu oil contains a wide variety of fatty acids, including high lauric and myristic acid concentrations, ${ }^{14}$ but lauric acid is the main component responsible for the therapeutic properties of the plant. ${ }^{15}$ Despite several studies of the properties of the plant and its products, the activity of babassu oil as a possible delivery system has not yet been elucidated. The aim of this study was to develop and characterize a babassu oil ME system and verify the effects of an ME on the functional activity of phagocytes.

\section{Materials and methods System composition}

The MEs were formulated using distilled water; babassu oil, with a hydrophilic-lipophilic balance (HLB) of 10.0 (Mundo dos Óleos, Brasilia DF, Brazil); Sorbitan monooleate, Span ${ }^{\circledR}$ 80 (SP), with an HLB of 4.3 (Emfal, Betim, Brazil); Polysorbate 80 , Tween $80^{\circledR}$ (TW) with an HLB of 15.0 (Vetec, Rio de Janeiro, Brazil), and 1-butanol (BT) (Vetec). The system is abbreviated as SP/TW/BT.

\section{Determination of surfactant mixing ratio}

To act as a cosurfactant, BT was used in a ratio equivalent to $10 \%\left(\mathrm{~F}_{\mathrm{c}}=1\right)$ of the surfactant mixture. The HLB of the surfactant mixture and the composition required to achieve an HLB corresponding to the oily phase was calculated. The HLB of the SP and TW surfactants were taken into account, according to Ribeiro et al. ${ }^{16}$

\section{Development of the ME system}

Development of formulations utilized pre-established quantities of the components in which each component ranged from $20 \%$ to $80 \%$. The samples were visually rated after 72 hours at $25^{\circ} \mathrm{C}$ in the following regions: liquid, gelling, emulsion liquid, gel emulsion, and phase separation.
Titrations were performed on aqueous mixtures with surfactant/oil phase mass ratios of 1:9 and 9:1 under agitation to obtain the delimiting points, area and classification of different systems to form the diagram regions. The titration was performed by adding distilled water in quantities between $0.05 \mathrm{~mL}$ and $0.20 \mathrm{~mL}$. During this process, the mixture was agitated both manually and mechanically. After homogenization of each titrant, the formulation volumes were visually classified.

\section{Pseudoternary phase diagram construction}

Pseudoternary diagrams were constructed from the sample and titration data using SigmaPlot version 8.0 software. In the diagram, the superior vertex represents $100 \%$ surfactant/ cosurfactant, the lower right represents $100 \%$ oil phase, and the lower left represents $100 \%$ aqueous phase.

\section{Preselection of systems}

After acquisition of the pseudoternary diagram, composition of the systems that fall into the ME liquid region can be determined. This region contained preselected points that were distributed in lines dividing the region to achieve representative samples of the studied systems.

\section{Rheological characterization}

Rheological parameters were measured using a modular compact rheometer (MCR 102, Anton Paar Germany GmbH, Ostfildern, Germany) according to França et al. ${ }^{17}$ In all of the experiments, $600 \mu \mathrm{L}$ of ME was added to the surface of the reading plate, and the excess sample was removed. Readings were taken with continuous control of the gap measurement with the supported TruGap ${ }^{\mathrm{TM}}$ in $0.099 \mathrm{~mm}$. The measuring cell was a Toolmaster ${ }^{\mathrm{TM}} \mathrm{CP} 50$, and precise temperature control was achieved with T-Ready ${ }^{\mathrm{TM}}$. The data were compiled using Rheoplus V3.61 software. Graphics were also obtained using Rheoplus software. The flow and viscosity curves were based on established parameters for the control of shear stress $(\tau)$ to $0-5 \mathrm{~Pa}$ for the upsweep and 5-0 Pa for the curve downward. These tests were conducted under isothermal conditions at $25^{\circ} \mathrm{C}$, and 75 readings were taken for analysis.

The viscosity curve was taken using established parameters that were relative to temperature and based on fixed control shear stress $(\tau)$ to $1 \mathrm{~Pa}$ with variation in temperature from $5^{\circ} \mathrm{C} \pm 0.1^{\circ} \mathrm{C}$ to $45^{\circ} \mathrm{C} \pm 0.1^{\circ} \mathrm{C}$ and a heating rate of $1^{\circ} \mathrm{C}$ per minute. Parameters were recorded every $0.5^{\circ} \mathrm{C} \pm 0.1^{\circ} \mathrm{C}$, and 41 readings were taken for analysis. 


\section{Physicochemical characterization}

A method to verify the physicochemical parameters was designed to test the suitability of the formulations to act as delivery vehicles and to perform the initial characterization of each sample. This method verified the physical and chemical parameters of the formulations 24 hours after preparation and at the end of the stability study; the tests were performed in triplicate $(\mathrm{n}=3)$.

Aliquots of some preselected vehicles were centrifuged (Baby I, Fanem, São Paulo, Brazil) at 1,570 $\times g$ for 30 minutes at room temperature. After centrifugation, the samples with visual heterogeneity were excluded.

The $\mathrm{pH}$ of the vehicles was determined with a $\mathrm{pH}$ meter (Del Lab, Campinas, Brazil) that was calibrated with standard $\mathrm{pH} 7$ and $\mathrm{pH} 4$ solutions. The electrical conductivity was measured using a conductivity meter (Lida, São Paulo, Brazil) calibrated with a $0.1 \mathrm{~mol} / \mathrm{L} \mathrm{KCl}$ solution to identify the system type (water in oil or oil in water) and any tendency toward phase inversion.

\section{Stability studies}

Samples were divided into two groups according to temperature: those that were refrigerated at $5^{\circ} \mathrm{C} \pm 1^{\circ} \mathrm{C}$ and those that were heated to $40^{\circ} \mathrm{C} \pm 1^{\circ} \mathrm{C}$. These systems were preliminarily subjected to alternating cycles of $5^{\circ} \mathrm{C} \pm 1^{\circ} \mathrm{C}$ and $40^{\circ} \mathrm{C} \pm 1^{\circ} \mathrm{C}$ for 24 hours each, with the cycles completed on the 14th day. After the cycle, it was possible to identify the most thermodynamically stable formulations.

The formulations were subjected to extreme conditions to determine their stability over a long period. The systems were divided into three groups according to temperature: $5^{\circ} \mathrm{C} \pm 1^{\circ} \mathrm{C}, 25^{\circ} \mathrm{C} \pm 1^{\circ} \mathrm{C}$, and $40^{\circ} \mathrm{C} \pm 1^{\circ} \mathrm{C}$. The groups were assessed in triplicate for a period of 90 days. Every 30 days, the formulations were maintained at room temperature for 24 hours to determine the physicochemical properties and to reassess the rheological profiles.

\section{Dynamic light scattering}

Colloidal suspensions of formulation 2B were prepared for analysis by the dynamic light scattering technique. It was then possible to investigate the hydrodynamic diameter of the dispersed solid. The samples were prepared from a 1:1,000 dilution of the formulation in deionized water in quartz cuvettes using deionized water as the reference. Dynamic light scattering analyses were performed using a Zetasizer Nano Z90 (Malvern Instruments, Malvern, UK) with excitation at $632.8 \mathrm{~nm}$.
Modulation of blood phagocyte functional activity by babassu oil ME

\section{Blood sampling and blood cell separation}

Blood samples $(10 \mathrm{~mL})$ were collected from 20 volunteer donors in tubes with anticoagulant. This study was approved by the institutional research ethics committee, and all of the subjects gave their written informed consent before entering the experimental protocol. The samples were centrifuged at $160 \times g$ for 15 minutes to separate plasma from the cells. Cells were separated over a Ficoll-Paque gradient (Pharmacia, Uppsala, Sweden), producing preparations with $95 \%$ pure mononuclear cells as analyzed by light microscopy. Purified monocytes were resuspended independently in serum-free Medium 199 (SigmaAldrich Co., St Louis, MO, USA) at a final concentration of $2 \times 10^{6}$ cells $/ \mathrm{mL}$. The cells were used immediately for superoxide release, phagocytosis, and microbicidal activity assays.

\section{Phagocyte treatment with babassu oil and ME}

To assess the effect of babassu oil (Mundo dos Óleos) and ME on superoxide anion release, phagocytosis, and microbicidal activity, mononuclear phagocytes $\left(2 \times 10^{6}\right.$ cells $\left./ \mathrm{mL}\right)$ were incubated with $20 \mu \mathrm{L}$ (final concentration $100 \mathrm{ng} / \mathrm{mL}$ ) and immediately used in the assays. A control was performed with Medium 199 only.

\section{Escherichia coli strain}

The enteropathogenic E. coli (EPEC) used was isolated from stools of an infant with acute diarrhea (serotype 0111: $\left.\mathrm{H}^{-} A L^{-}, e a e^{+}, e a f^{+}, b f p^{+}\right)$. This material was prepared and adjusted to $10^{7}$ bacteria $/ \mathrm{mL}$, as previously described by Honorio-França et al. ${ }^{18}$

\section{Superoxide anion release}

Superoxide release was determined by reduction of cytochrome C (Sigma-Aldrich, St Louis, MO, USA) ${ }^{18}$ Briefly, mononuclear phagocytes and bacteria were mixed and incubated for 30 minutes to assess phagocytosis. Cells were then resuspended in phosphate-buffered saline containing 2.6 $\mathrm{mM} \mathrm{CaCl}, 2 \mathrm{mM} \mathrm{MgCl}$, after which cytochrome C (2 mg/ $\mathrm{mL})$ and babassu oil $(20 \mu \mathrm{L})$ or babassu ME $(20 \mu \mathrm{L})$ was added. The suspensions $(100 \mu \mathrm{L})$ were incubated for 1 hour at $37^{\circ} \mathrm{C}$ on culture plates. A control was performed using only the spontaneous release of cells. The reaction rates were measured by absorbance at $550 \mathrm{~nm}$, and the results were expressed as $\mathrm{nmol} / \mathrm{O}_{2}^{-}$. All of the experiments were performed in duplicate. 


\section{Cellular viability and bactericidal assay}

Cellular viability, phagocytosis, and microbicidal activity were evaluated using the acridine orange method. ${ }^{19}$ Equal volumes of bacteria and cell suspensions were mixed and incubated at $37^{\circ} \mathrm{C}$ for 30 minutes under continuous shaking. Phagocytosis was stopped by incubation on ice. To eliminate extracellular bacteria, the suspensions were centrifuged twice $\left(160 \times g, 10\right.$ minutes, $\left.4^{\circ} \mathrm{C}\right)$. Cells were resuspended in serum-free Medium 199 and centrifuged. The supernatant was discarded, and the sediment was stained with $200 \mu \mathrm{L}$ acridine orange ( $14.4 \mathrm{~g} / \mathrm{L}$; Sigma-Aldrich) for 1 minute. The sediment was resuspended in cold Medium 199, washed twice, and observed under immunofluorescence microscopy at $400 \times$ and $1,000 \times$ magnification.

The viability index was calculated by counting the number of orange-stained (dead) and green-stained (alive) cells out of 100. The phagocytosis index was calculated by counting the number of cells that ingested at least three bacteria in a pool of 100 cells. To determine the bactericidal index, we stained the slides with acridine orange and counted 100 cells with phagocytosed bacteria. The bactericidal index was calculated as the ratio between orange-stained (dead) and green-stained (alive) bacteria $\times 100$. All of the experiments were performed in duplicate.

\section{Statistical analysis}

Data were expressed as the mean \pm standard deviation. Statistically significant differences in superoxide anion release, phagocytosis, and bactericidal index in the presence or absence of ME were evaluated using analysis of variance; statistical significance was considered for a $P$-value $<0.05$.

\section{Results}

\section{Determination of surfactant mixing ratio}

The concentration of cosurfactant BT was defined as $10 \%$, and the percentage of surfactant SP and TW were calculated to achieve the required babassu oil HLB. The surfactant mixture (SP/TW/BT) was 4.2:4.8:1.0 to achieve the required HLB, which was the same as the oily phase.

\section{ME system development}

Pseudoternary phase diagrams were assembled to classify the points, and domains of each region are demonstrated in Figure 1. The SP/TW/BT (4.2/4.8/1.0) surfactant mixture was compared with babassu oil and distilled water in proportions that were established by the diagram; these data resulted in 36 points with divergent equilibrium characteristics. It was observed that with over $40 \%$ of surfactants, the thermodynamic equilibrium became efficient because homogeneous and translucent systems predominated (Figure 1A).

Figure 1B shows the pseudoternary diagram with delimited domains from the diagram points and aqueous titrations. The formulations were preselected from the ME liquid region to study the SP/TW/BT. Analysis of the phase behavior indicated that large range surfactant compositions produced stable systems. When the domain surfactant concentration was below $55 \%$, some instability and phase separation were also observed, indicating that these surfactant concentrations could not balance high proportions of aqueous and oily phases (Figure 1B). Formulations 1-16 exhibited characteristics of ME liquid (Figure 2A), whereas the formulations of 17-36 exhibited characteristics of ME gel or phase separation (Figure 2B).

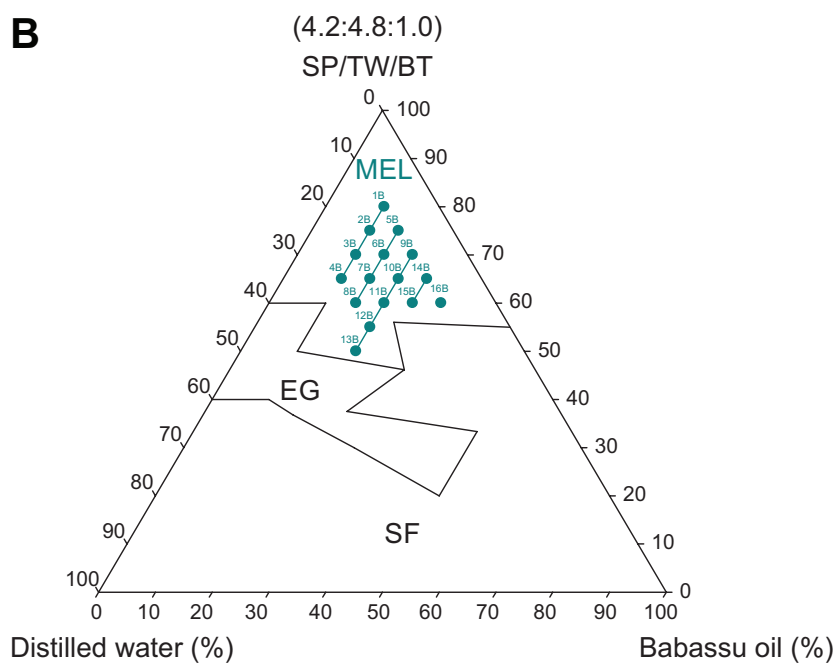
Distilled water (\%)

(4.2:4.8:1.0)

SP/TW/BT

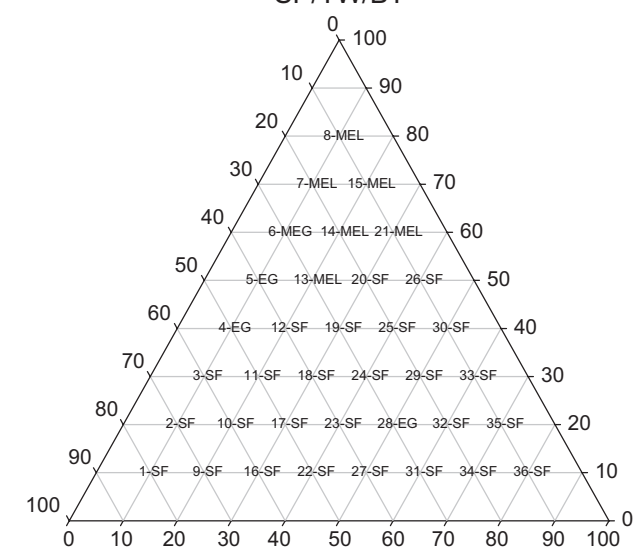

Babassu oil (\%)

Figure I Diagram of the pseudoternary classification of all 36 points in pre-established proportions (A) and domains with points selected for the study system SP/TW/BT (B). Abbreviations: MEL, microemulsion liquid; MEG, microemulsion gel; EG, emulsion gel; SF, phase separation; SP, Sorbitan monooleate-Span 80; TW, Polysorbate 80-Tween $80^{\circledR}$; BT, I-butanol. 

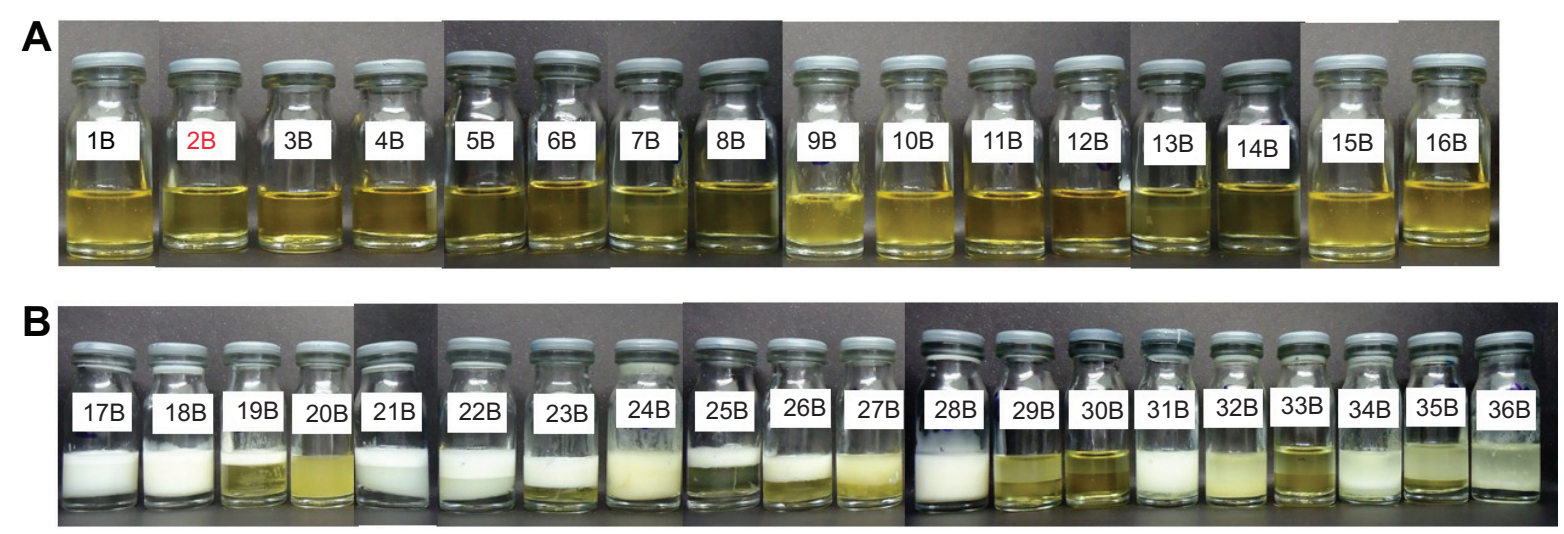

Figure 2 Formulations of study system SP/TW/BT [4.2/4.8/I.0] of 36 points with divergent equilibrium characteristics. Microemulsion liquid (A), microemulsion gel or phase separation (B).

Abbreviations: SP, Sorbitan monooleate-Span 80; TW, Polysorbate 80-Tween 80®; BT, I-butanol.

\section{Rheological characterization}

Formulations 12B, 13B, 14B, 15B, and 16B were observed to show nonlinear flow and viscosity (Figure $3 \mathrm{~A}$ and $\mathrm{B}$ ), and these formulations were discarded. The stable formulations (1B, 2B, 3B, 4B, 5B, 6B, 7B, 8B, 9B, 10B, and 11B) present in the flow curve began at the origin and then exhibited linear ascending and descending behavior (Figure 3A). This behavior indicates that the formulations are Newtonian fluids.
Viscosity was similar between the formulations and ranged from 0.20 to $0.40 \mathrm{~Pa}$. Formulation 5B demonstrated increased viscosity (Figure 3B).

Figure 4 demonstrates data for stable formulation viscosity variation versus temperature scanning. The viscosity changed with temperature. All of the formulations displayed a gradual reduction in viscosity with increased temperature. For temperatures below $20^{\circ} \mathrm{C}$, the MEs demonstrated

A

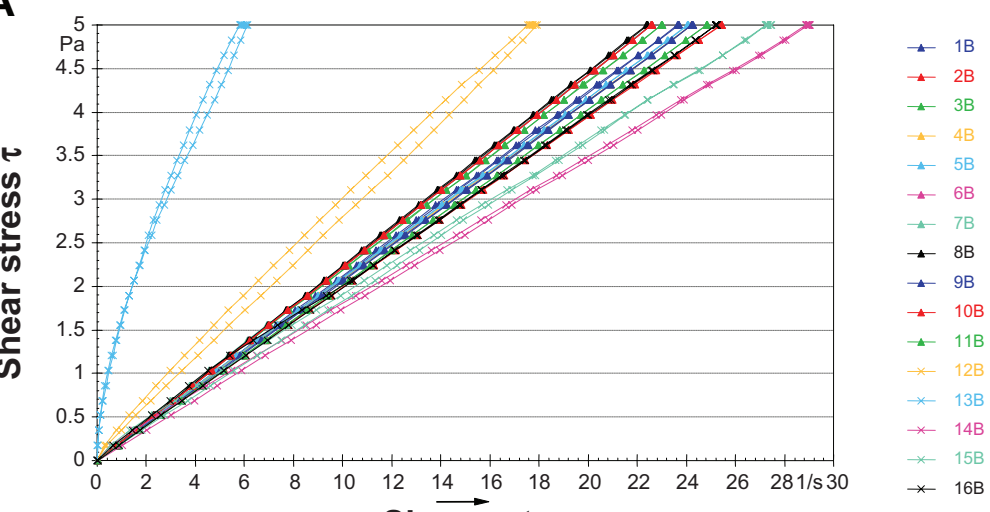

B

Shear rate $\gamma$

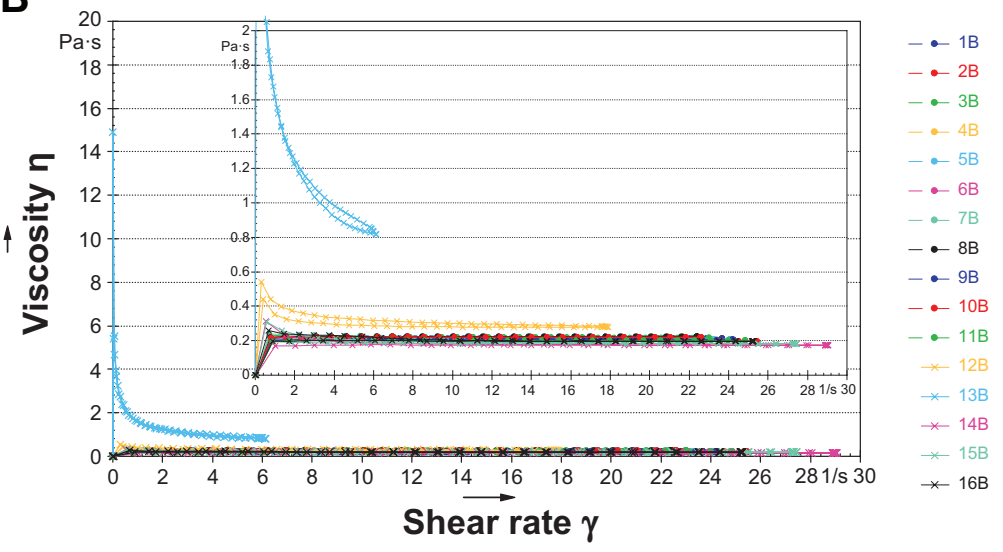

Figure 3 Flow curves $(\mathbf{A})$ and formulation viscosity $(\mathbf{B})$ during the preliminary stability period $\left(25^{\circ} \mathrm{C}\right)$. 
fluctuations in viscosity, indicating less uniformity and a greater tendency to destabilize, whereas at temperature between $20^{\circ} \mathrm{C}$ and $45^{\circ} \mathrm{C}$, the formulations demonstrated linear and stable flow curves.

Evaluation of formulation rheological behavior and maintenance over time during the accelerated stability study is presented in Figure 5. All of the formulations that were submitted to the accelerated stability study demonstrated a similar profile both in flow curve and viscosity. Formulations $5 \mathrm{~B}$ and $6 \mathrm{~B}$ exhibited a rheological profile during 30 days, $10 \mathrm{~B}$ for 45 days, and 1B, 2B, and 3B were stable for 90 days (Figure 5A and B).

\section{Physicochemical analysis}

The results of a physicochemical analysis after temperature cycling for the stable formulations are demonstrated in Table 1. Formulations 4B, 8B, and 11B displayed macroscopic instability after centrifugation, and formulations $7 \mathrm{~B}$ and 9B displayed changes in translucence under refrigeration; further stability tests for these samples could not be pursued.

All of the formulations were classified as oil in water because they had electrical conductivity values above that of distilled water $(>1.3 \mu \mathrm{S} / \mathrm{cm})$. The $\mathrm{pH}$ values obtained before and after the test remained between 6.3 and 6.8 .

The physicochemical analyses of the formulations in accelerated stability conditions are presented in Table 2. Formulations 5B, 6B, 9B, and 10B exhibited macroscopic instability after 30 days. Only formulations 1B, 2B, and $3 \mathrm{~B}$ remained with MEs during the entire test. The $\mathrm{pH}$ values obtained revealed little variation from $\mathrm{pH} 6.6$ to 7.1 . Formulations demonstrated minor changes in conductivity and retained oil in water characteristics over the entire trial period.

According to rheological parameters and physicochemical analysis, the 2B formulation (10\% oil, 15\% water, and $75 \%$ surfactants) remained more stable (Figure 2A). Thus, the results were conducted with this formulation.

\section{Hydrodynamic diameter}

The hydrodynamic diameter values that were obtained in the developed formulation are shown in Figure 6. The results show the histogram distribution of the hydrodynamic diameter of formulation that resulted in a mean diameter of $277.40 \mathrm{~nm}$.

\section{Superoxide release}

Superoxide release increased when the mononuclear phagocytes were treated with oil or ME in the presence or absence of bacteria compared with spontaneous release. The highest superoxide concentrations regardless of bacterial presence were observed when phagocytes were incubated with the ME (Table 3).

\section{Phagocyte viability index}

The viability index was higher when the cells were incubated with the babassu oil ME. Cells incubated only with oil demonstrated a similar viability index to that obtained when cells were incubated with culture medium (Table 4).

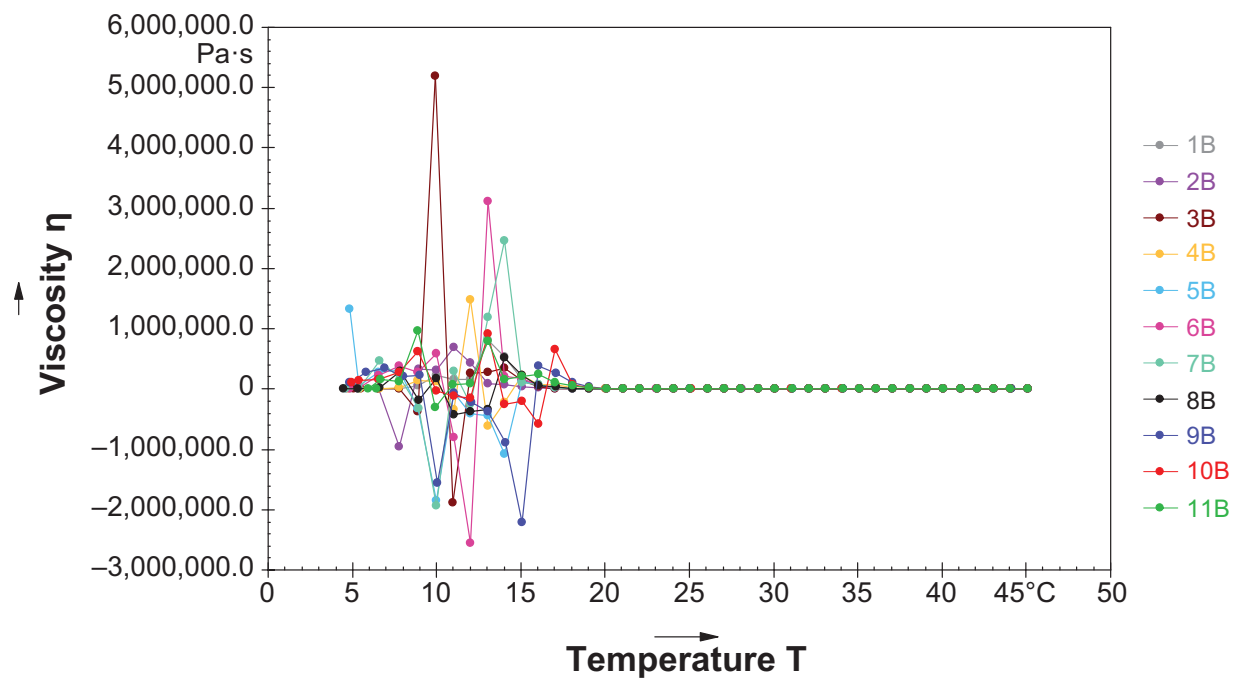

Figure 4 Viscosity curves with respect to temperature $\left(5^{\circ} \mathrm{C}-45^{\circ} \mathrm{C}\right)$ for stable formulations with the SP/TW/BT system. Abbreviations: SP, Sorbitan monooleate-Span 80 ${ }^{\circledR}$; TW, Polysorbate 80-Tween $80^{\circledR}$; BT, I-butanol. 
A

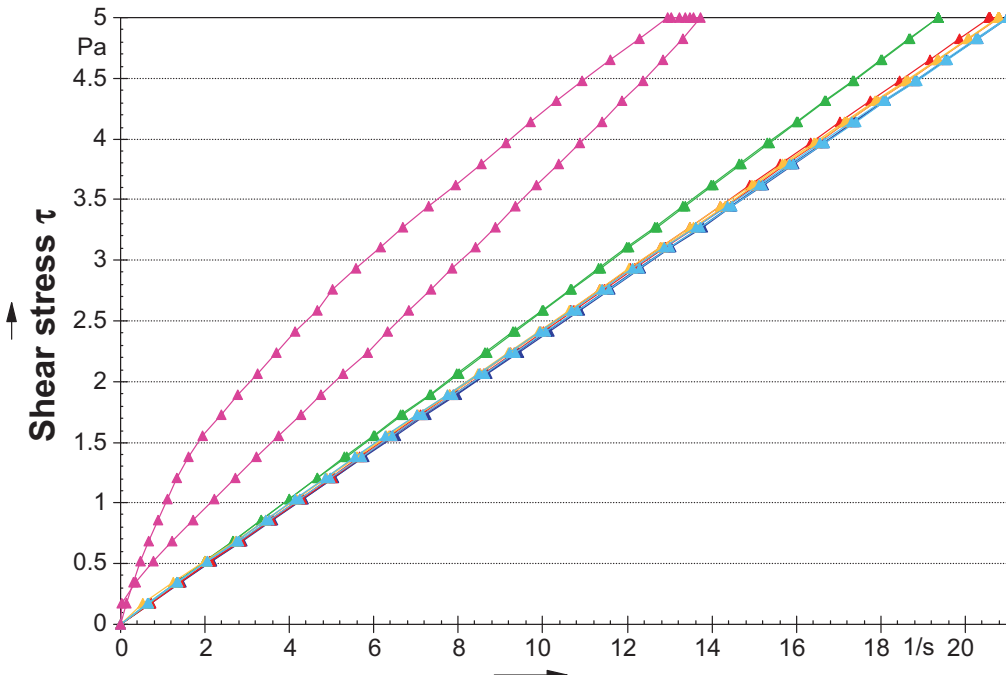

Shear rate $\gamma$

B

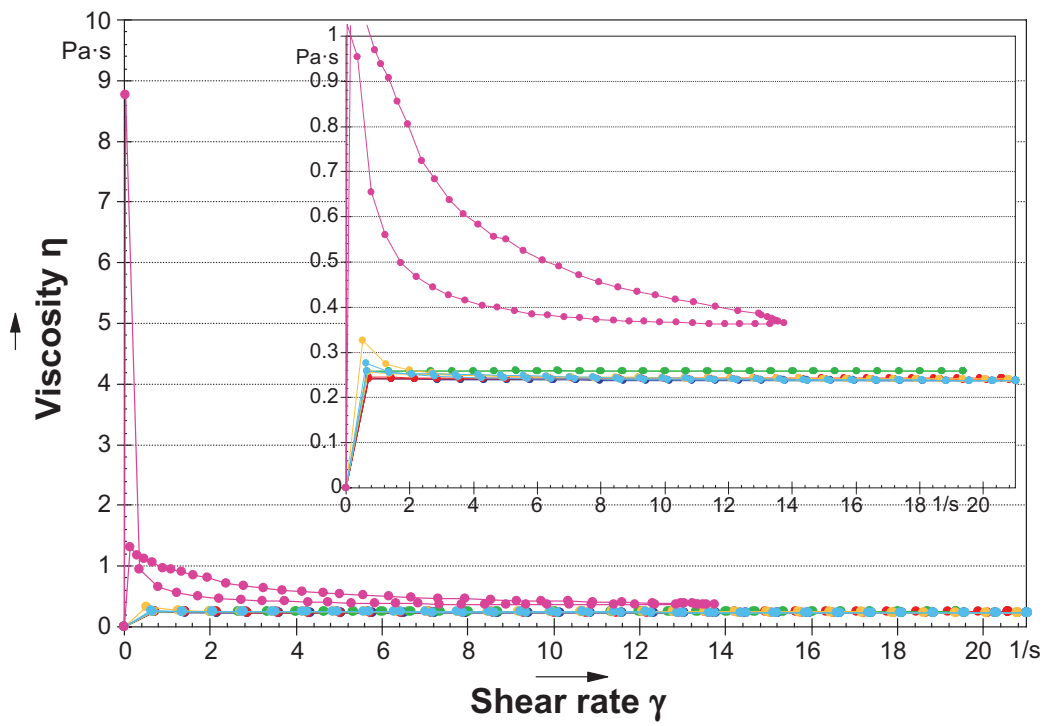

1B $(0,30,60,90$ days; $P=0.6275)$ 2B $(0,30,60,90$ days; $P=0.0648)$ 3B $(0,30,60,90$ days; $P=0.0605)$ $5 \mathrm{~B}$ (30 days) 6B (30 days) 10B (>30 days)

1B $(0,30,60,90$ days; $P=0.6275)$ 2B (0, 30, 60,90 days; $P=0.0648)$ 3B $(0,30,60,90$ days; $P=0.0605)$ $5 \mathrm{~B}$ (30 days) 6B (30 days) 10B (>30 days)

Figure 5 Flow curves (A) and viscosity (B) of formulations during the accelerated stability period $\left(25^{\circ} \mathrm{C}\right)$.

Table I Physicochemical analysis for preliminary formulation

\begin{tabular}{|c|c|c|c|c|c|}
\hline \multirow[t]{2}{*}{ Formulation } & \multirow[t]{2}{*}{ Centrifugation analysis } & \multicolumn{2}{|c|}{ Conductivity $(\mu \mathrm{S} / \mathrm{cm})$} & \multicolumn{2}{|l|}{$\mathrm{pH}$} \\
\hline & & Before & After & Before & After \\
\hline IB & $N$ & 8.95 & 7.915 & 6.33 & 7.51 \\
\hline $2 B$ & $N$ & 13.33 & 22.45 & 6.33 & 6.92 \\
\hline 3B & $N$ & 47.25 & 41.9 & 6.33 & 6.88 \\
\hline $4 \mathrm{~B}$ & A & 92.35 & 57.15 & 6.33 & 6.60 \\
\hline $5 B$ & $\mathrm{~N}$ & 11.06 & 11.86 & 6.33 & 6.92 \\
\hline $6 \mathrm{~B}$ & $\mathrm{~N}$ & 15.02 & 12.35 & 6.33 & 6.58 \\
\hline 7B & $\mathrm{N}$ & 56.35 & 46.75 & 6.33 & 6.59 \\
\hline $8 \mathrm{~B}$ & A & 110.5 & 77.15 & 6.33 & 6.55 \\
\hline $9 B$ & $\mathrm{~N}$ & 11.4 & 9.17 & 6.33 & 6.88 \\
\hline IOB & $N$ & 33.15 & 24.52 & 6.33 & 6.87 \\
\hline IIB & A & 65.65 & 55.55 & 6.33 & 6.40 \\
\hline
\end{tabular}

Abbreviations: $\mathrm{N}$, normal; $\mathrm{A}$, altered. 
Table 2 Physicochemical analysis for accelerated formulation

\begin{tabular}{|c|c|c|c|c|c|c|c|c|}
\hline \multirow[t]{3}{*}{ Formulation } & \multicolumn{8}{|c|}{ Time (days) } \\
\hline & \multicolumn{2}{|l|}{0} & \multicolumn{2}{|l|}{30} & \multicolumn{2}{|l|}{60} & \multicolumn{2}{|l|}{90} \\
\hline & $\mathrm{pH}$ & $\begin{array}{l}\text { Conductivity } \\
(\mu \mathrm{S} / \mathrm{cm})\end{array}$ & $\mathrm{pH}$ & $\begin{array}{l}\text { Conductivity } \\
(\mu \mathrm{S} / \mathrm{cm})\end{array}$ & $\mathrm{pH}$ & $\begin{array}{l}\text { Conductivity } \\
(\mu \mathrm{S} / \mathrm{cm})\end{array}$ & $\mathrm{pH}$ & $\begin{array}{l}\text { Conductivity } \\
(\mu \mathrm{S} / \mathrm{cm})\end{array}$ \\
\hline $\mathrm{IB}^{*}$ & 6.94 & 12.13 & 6.94 & 9.63 & 6.60 & 8.17 & 7.07 & 10.04 \\
\hline $2 B^{*}$ & 6.88 & 24.00 & 6.77 & 19.35 & 6.89 & 22.07 & 6.98 & 20.28 \\
\hline $3 B^{*}$ & 6.76 & 31.80 & 6.74 & 36.20 & 6.92 & 41.83 & 6.84 & 36.73 \\
\hline $5 B$ & 6.66 & 11.20 & 6.94 & 8.67 & Deleted by alteration & & & \\
\hline $6 B$ & 6.83 & 24.20 & 6.83 & 18.92 & Deleted by alteration & & & \\
\hline $9 \mathrm{~B}$ & 7.60 & 10.25 & 7.01 & 8.13 & Deleted by alteration & & & \\
\hline $10 B$ & 6.94 & 27.30 & 6.88 & 21.53 & Deleted by alteration & & & \\
\hline
\end{tabular}

Note: *Stable formulations during all periods.

\section{Phagocytosis and microbicidal activity}

Phagocytosis of cells in the presence of oil or ME is demonstrated in Table 4. Blood cells, irrespective of treatment with babassu oil or ME, increased phagocytosis. Babassu oil increased the microbicidal activity of mononuclear blood phagocytes compared with untreated phagocytes. ME in the presence of phagocytes showed increased microbicidal rates compared with untreated cells, but lower microbicidal activity when compared with cells treated with babassu oil (Table 4) ME babassu oil-mediated bacterial killing by mononuclear phagocytes is shown in Figure 7.

\section{Discussion}

In this study, we developed a liquid ME formulation from babassu oil with diagrams that demonstrated linear oil phase viscosity and a Newtonian profile. It was classified as oil-towater, had a biocompatible $\mathrm{pH}$, and was nontoxic, stable, and capable of interacting with blood phagocytes.

The stability of emulsion systems depends intrinsically on interphase interactions established by the emulsifier agent and between the immiscible phases that constitute them. The selection and characteristic ratio of surfactant to be used in the preparation are determined by verifying the HLB of substances, which allows for evaluation of the expected behavior of the compound across polar and nonpolar compounds. ${ }^{3}$

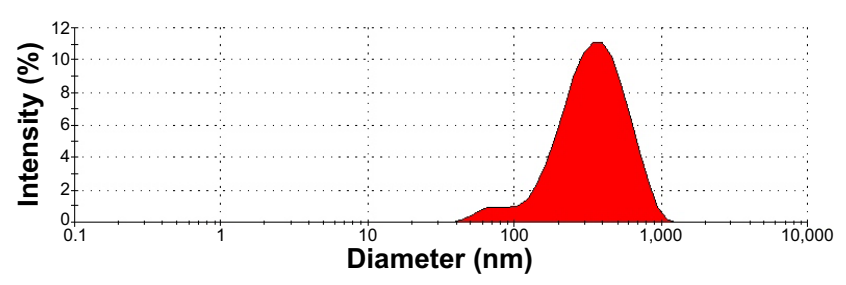

Figure 6 Hydrodynamic diameter of the formulations.
The HLB values for a mixture of surfactants possibly indicates that the systems have a certain classification phase, ie, oil in water or water in oil, during preparation of stable systems. The combination of surfactants also provides HLB values closest to the required HLB in the oily phase. ${ }^{2,16}$ In this study, the mixture of surfactants used for development of the system was SP/TW/BT in a ratio of 4.2:4.8:1.0, which provided an HLB value equal to what was required by babassu oil, which is 10.0. The literature has reported that substances with an HLB between 9 and 16 exhibit hydrophilic characteristics and produce oil in water emulsions. ${ }^{20}$

Studies have reported that a high HLB indicates more hydrophilic properties and provides lower core growth and a smaller final particle size. ${ }^{20}$ These observations are theoretically expected because correct HLB adjustment can produce systems with a small particle diameter, thereby generating systems with higher thermodynamic stability. ${ }^{21}$

The phase diagrams indicate that formation of ME regions and emulsified liquid crystalline varies with the proportions of the constituents, and these regions may be conducted in accordance with the applicability to delivery system development. ${ }^{22}$

Table 3 Superoxide release by blood mononuclear phagocytes

\begin{tabular}{ll}
\hline Mononuclear phagocytes & Superoxide release (nmol) \\
\hline Spontaneous & $3.6 \pm 0.4$ \\
Oil (babassu) & $4.3 \pm 0.7^{*}$ \\
Microemulsion (babassu) & $22.9 \pm 2.4^{*}$ \\
Bacteria & $4.6 \pm 0.4^{*}$ \\
Bacteria + oil (babassu) & $5.6 \pm 0.5^{*}$ \\
Bacteria + microemulsion (babassu) & $22.0 \pm 4.0^{*}$ \\
\hline
\end{tabular}

Notes: The results are shown as the mean \pm standard deviation ( $\mathrm{n}=8$ in each treatment). Blood mononuclear cells were treated or not treated with babassu oil or microemulsion in the presence or absence of enteropathogenic Escherichia coli. *Indicates differences between phagocytes treated (babassu oil and microemulsion) and incubated with bacteria and the control (without bacteria). 
Table 4 Viability of cells (\%), phagocytosis and bactericidal indices by blood mononuclear phagocytes as determined by the acridine orange method

\begin{tabular}{llll}
\hline Mononuclear phagocytes & Viability (\%) & Phagocytosis index (\%) & Bactericidal index (\%) \\
\hline Medium I99 & $93.2 \pm 2.4$ & $47.0 \pm 13.9$ & $21.6 \pm 9.5$ \\
Oil (babassu) & $94.3 \pm 3.1$ & $63.5 \pm 9.4^{*}$ & $47.9 \pm 15.4^{*}$ \\
Microemulsion (babassu) & $98.0 \pm 0.8^{*}$ & $69.1 \pm 12.3^{*}$ & $31.8 \pm 5.2^{*}$ \\
\hline
\end{tabular}

Notes: The results are shown as the mean \pm standard deviation ( $n=8$ in each treatment). Phagocytes were incubated with enteropathogenic Escherichia coli in the presence of babassu oil and microemulsion. *Indicates differences from the Medium 199 and treatment (babassu oil and microemulsion).

In this study, phase diagram construction resulted in systems with various characteristics and organization types from a wide range of component combinations. The regions defined in the diagram were dependent on the surfactant concentration. Low surfactant concentrations did not stabilize component mixtures, leading to phase separation, while at higher concentrations, emulsion systems were formed, indicating that higher concentrations of surfactant may maintain the stability of the system.

Parameters indicating physical and chemical stability of emulsions and MEs can be measured by rheological analysis; this technique provides data that are relevant to product structure and allow changes that result in destabilization. ${ }^{23}$ Of the 16 formulations that were submitted to rheological tests, only formulation 11 demonstrated a Newtonian profile.

According to the literature, viscosity is largely influenced by controlled-release systems associated with change of temperature. ${ }^{2,17}$ In this study, the rheological behavior of the formulations at different temperatures was characteristic of babassu oil, which is rich in lauric acid, demonstrating altered viscosity and flow curves at temperatures below $25^{\circ} \mathrm{C} .{ }^{24}$

In addition to rheological characteristics, other stability studies were performed by physical and chemical analyses. ${ }^{25}$ Several factors are involved in this process, including physical (temperature, agitation, freezing, centrifugation), chemical ( $\mathrm{pH}$, presence of electrolytes, lipid peroxidation), contamination by micro-organisms, and composition of the system. $^{26}$

In this study, formulations $4 \mathrm{~B}, 8 \mathrm{~B}, 12 \mathrm{~B}$, and $13 \mathrm{~B}$ demonstrated macroscopic instability after centrifugation at a $\mathrm{pH}$ of 6.3-6.8 and 6.9-7.1 in preliminary and accelerated stability, respectively. All points and formulations that were studied maintained the oil in water profile after thermal stress. Thus, on the basis of rheological and physicochemical characteristics, the $2 \mathrm{~B}$ formulation remained more stable.

Light scattering is a routine technique to determination the diameter of the internal phase of MEs. ${ }^{3,4}$ In this study the $2 \mathrm{~B}$ microemulsion showed diameters with a mean of $277.40 \mathrm{~nm}$. The literature showed the diameters of the structures to be dependent on the ratio of surfactant and oil phase of ME. ${ }^{22}$ Occurs the formation of nanoscale structures and hydrodynamic diameter decrease when the surfactant proportion predominate over the oil phase..$^{3,21-23}$ These results reinforce the biocompatibility of the system developed.

In contrast, studies have demonstrated that ME systems can be valuable for release of plants with medicinal characteristics $^{2,13}$ as well as for use as vaccine adjuvants. ${ }^{1}$ The biological effects of medicinal plants have been validated by research demonstrating microbicidal, ${ }^{8,17}$ anthelmintic, ${ }^{27}$ antiseptic, ${ }^{28}$ anti-inflammatory, ${ }^{12}$ and immunomodulatory effects. ${ }^{9}$

In this study, the viability of mononuclear blood phagocytes did not change in the presence of the
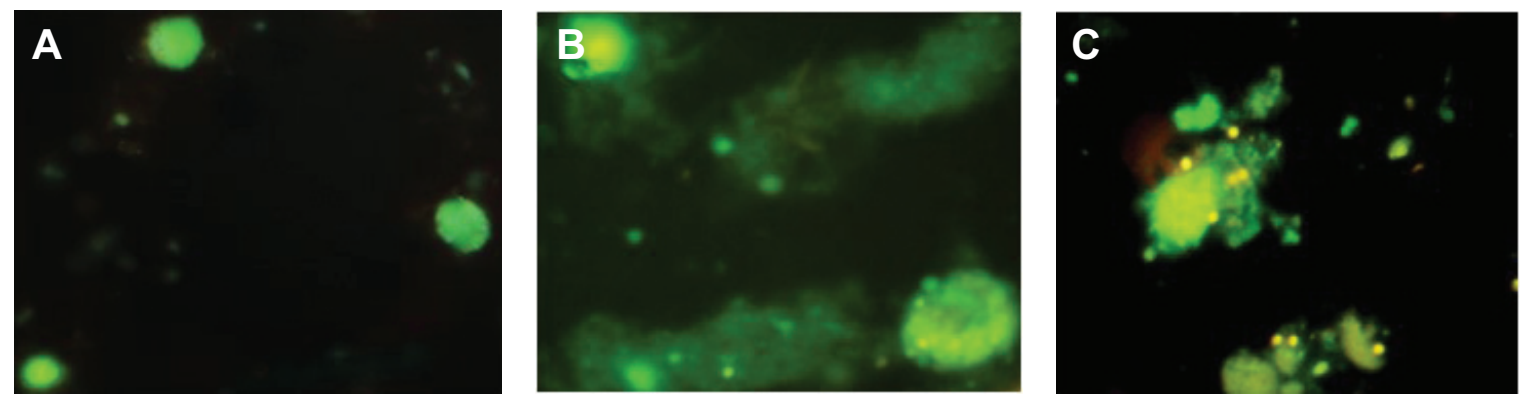

Figure 7 Bacterial killing by mononuclear phagocytes in the presence of microemulsion babassu oil.

Notes: Mononuclear phagocytes viability $(\mathbf{A})$. The mononuclear phagocytes was incubated with bacteria and stained with acridine orange and analyzed by fluorescent microcopy. Orange-stained bacteria (dead) and green-stained bacteria (alive). Phagocytosis of bacteria (B) and bacterial killing (C). 
babassu oil ME. Several other groups have also related cell viability to functional activity, demonstrating that stimuli such as medicinal plants ${ }^{10,29,30}$ and hormones ${ }^{31}$ can increase release of superoxide anions from mononuclear phagocytes.

Generation of free radicals is reportedly an important organismal defense mechanism during infectious processes. ${ }^{20,32-34}$ In this work, we found that both ME and babassu oil increased release of superoxides from human blood phagocytes. These data are in agreement with the literature, $, 10,18$ in which babassu oil had an immunostimulatory action on superoxide release by phagocytes.

The literature reports that increased superoxide release by phagocytic cells is associated with increased phagocytic and bactericidal activity. ${ }^{19,35}$ However, the use of EPEC is an adequate model in which to analyze the functional activity of phagocytes in the presence of a modified-delivery system. ${ }^{10,29-31}$ Phagocytosis and the microbicidal activity of phagocytes, with production of active oxygen metabolites such as free radicals, comprise an important defense mechanism against a number of bacterial, ${ }^{18,19,35}$ fungal, ${ }^{36}$ and protozoal infections ${ }^{37}$ Here, the babassu oil and ME system increased the phagocytosis of EPEC, which was reflected in microbicidal mechanisms. Conversely, the babassu oilinduced stimulation of microbicidal activity determined prooxidative effects and subsequent EPEC killing, suggesting an important immunomodulatory role for this oil. Interestingly, nutraceutical preparations can contain expressive amounts of bioactive compounds which can decrease diseases, ${ }^{38,39}$ and increase immunostimulatory activity. Some bioactive compounds from nutraceuticals can modulate and improve immune function. ${ }^{40}$

Phagocytes produce superoxide-generating oxidants that act as microbicides, which are produced to combat invading micro-organisms; however, they can cause damage and participate in a large number of diseases. Maintenance of antioxidant defenses related to formation of reactive oxygen species is necessary for the survival of organisms and preventing inflammatory processes. ${ }^{41}$

Research on natural antioxidants has been intensified. ${ }^{30,34}$ In this study, the babassu ME formulation modulated the functional phagocytic activity. More studies should be conducted to verify the potential of this formulation as an adjuvant for delivery of vaccines.

In conclusion, babassu oil is a natural product, is easy to obtain, and can be added to the diet, so may be an alternative for future immunotherapy applications, in particular for infectious diseases. The babassu oil ME system is an alternative for possible use as an adjuvant or in modified drug delivery systems.

\section{Acknowledgments}

The authors are very grateful to Dr Maria Aparecida Godoy Soler for technical assistance in dynamic light scattering. This work was supported by the Conselho Nacional de Desenvolvimento Científico e Tecnológico, Brazil, the Fundação de Apoio a Pesquisa de Mato Grosso, and DINTER in Parasitology UFMT/UFMG, Coordenação de Aperfeiçoamento de Pessoal de Nível Superior, Brazil.

\section{Disclosure}

The authors report no conflicts of interest in this work.

\section{References}

1. Saroja CH, Lakshmi PK, Bhaskaran S. Recent trends in vaccine delivery systems: a review. Int J Pharm Investig. 2011;1:64-74.

2. Chaud NG, França EL, Ribeiro EB, Pessoa RS, Lanes PK, Honorio-França AC. [Development and characterization of a neomaterial based microemulsion as a vehicle of Lippia sidoides]. SODEBRAS. 2014;9:31-38. Available from: http://sodebras.com.br/edicoes/N98.pdf. Accessed November 19, 2014. Portuguese.

3. Lawrence MJ, Rees GD. Microemulsion-based media as novel drug delivery systems. Adv Drug Deliv Rev. 2000;64:175-193.

4. Kreilgaard M. Influence of microemulsion on cutaneous drugs delivery. Adv Drug Deliv Rev. 2002;54:77-98.

5. Akagi T, Baba M, Akashi M. Biodegradable nanoparticles as vaccine adjuvants and delivery systems: regulation of immune responses by nanoparticle-based vaccine. Adv Polym Sci. 2012;247:31-64.

6. Batista CP, Torres OJ, Matias JE, et al. [Effect of watery extract of Orbignya phalerata (babassu) in the gastric healing in rats: morphological and tensiometric study]. Acta Cir Bra. 2006;21 Suppl 3:26-32. Portuguese.

7. Pinheiro MM, Boylan F, Fernandes PD. Antinociceptive effect of the Orbignya speciosa Mart. (Babassu) leaves: evidence for the involvement of apigenin. Life Sci. 2012;91:293-300.

8. França EL, Maynie JC, Correa VC, et al. Immunomodulatory effects of herbal plants plus melatonin on human blood phagocytes. Int $J$ Phytomed. 2010;2:354-362.

9. França EL, Fagundes DLG, Leão LD, Honorio-França AC. [Effects of "mais vida", a commercial natural mix, on the activation of macrophages from diabetic rats]. Rev Bras Plantas Med. 2012;14:1-7. Portuguese.

10. Reinaque APB, França EL, Scherer EF, Cortês MA, Honorio-França AC. Natural material adsorbed onto a polymer to enhance immune function. Drug Des Devel Ther. 2012;6:209-216.

11. Amorim E, Matias JE, Coelho JC, et al. [Topical use of aqueous extract of Orbignya phalerata (babassu) in rats: analysis of its healing effect]. Acta Cir Bras. 2006;21 Suppl 2:67-76.

12. Martins NL, Malafaia O, Ribas-Filho JM, et al. [Healing process in cutaneous surgical wounds in rats under the influence of Orbignya phalerata aqueous extract]. Acta Cir Bras. 2006;21 Suppl 3:66-75. Portuguese.

13. Honorio-França AC, Moreira C, Boldrini F, França EL. [Evaluation of hypoglycemic activity and healing of extract from amongst bark of "Quina do Cerrado" (Strychnos pseudoquina ST. HILL)]. Acta Cir Bras. 2008;23:504-510. Portuguese.

14. Urioste D, Castro MB, Biaggio FC, Castro HF. Synthesis of chromatographic standards and establishment of a method for the quantification of the fatty ester composition of biodiesel from babassu oil. Quím Nova. 2008;31:407-412.

15. Yang D, Pornpattananangkul D, Nakatsuji T, et al. The antimicrobial activity of liposomal lauric acids against Propionibacterium acnes. Biomaterials. 2009;30:6035-6040. 
16. Ribeiro EB, Lanes PK, Chaud NG, Pessoa RS, Honorio-França AC, França EL. Microemulsions with levamisole delivery systems as novel immunomodulating agents with potential for amebiasis therapies. Sci Adv Mater. In press 2014.

17. França EL, Ribeiro EB, Scherer EF, et al. Effects of Momordica charantia L. on the blood rheological properties in diabetic patients. Bio Med Res Int. 2014;2014:840379.

18. Honorio-França AC, Carvalho MP, Isaac L, Trabulsi LR, Carneiro-Sampaio MM. Colostral mononuclear phagocytes are able to kill enteropathogenic Escherichia coli opsonized with colostral IgA. Scand J Immunol. 1997;46:59-66

19. França EL, Bittercourt R, Fijimori M, Moraes TC, Calderon IM, Honorio-França AC. Human colostral phagocytes eliminate enterotoxigenic Escherichia coli opsonized by colostrum supernatant. J Microbiol Immunol Infect. 2011;44:1-7.

20. Housaindokht MR, Pour AN. Study the effect of HLB of surfactant on particle size distribution of hematite nanoparticles prepared via the reverse microemulsion. Solid State Sci. 2012;14:622-625.

21. Aboofazeli R, Barlow DJ, Lawrence MJ. Particle analysis of concentrated phospholipidic microemulsions II. Photocorrelation spectroscopy. AAPS Pharm Sci. 2000;2:1-10.

22. Formariz TP, Urban MC, Silva AA Jr, Gremião MP, Oliveira AG. [Microemulsion and liquid crystals as drug delivery systems]. Revista Brasileira de Ciências Farmacêuticas. 2005;41:301-313. Portuguese.

23. Tadros T, Izquierdo P, Esquena J, Solans C. Formation and stability of nano-emulsions. Adv Colloid Interface Sci. 2004;108-109:303-318.

24. Castro AD, Braga ME, Cavalcanti-Mata ER. [Rheological behaviour of babaçu coconut oil in different temperatures]. Rev Bras Ol Fibros. 2002;6:457-463. Portuguese.

25. Jiao J, Burgess DJ. Rheology and stability of water-in-oil-in-water multiple emulsions containing Span 83 and Tween 80. AAPS Pharm Sci. 2003;5:E7.

26. Bruxel F, Laux M, Wild LB, Fraga M, Koester LS, Teixeira HF. Nanoemulsions as parenteral drug delivery systems. Quím Nova. 2012;35:1827-1840.

27. Souza CM, Brandão DO, Silva MS, Palmeira AC, Simões MO, Medeiros AC. [Use of medicinal plants with antimicrobial activity by users of the public health system in Campina Grande, Paraíba, Brazil]. Rev Bras Plantas Med. 2013;15:287-292. Portuguese.

28. Kaziyama VM, Fernandes MJ, Simoni IC. [Antiviral activity of commercially available medicinal plants on suid and bovine herpesviruses] Rev Bras Plantas Med. 2012;14:522-528. Portuguese.
29. Scherer EF, Honorio-França AC, Hara CC, Reinaque AP, Cortês MA França EL. Immunomodulatory effects of polyethylene glycolmicrospheres adsorbed with nanofractions of Momordica charantia L. on diabetic human blood phagocytes. Sci Adv Mater. 2011;3:687-694.

30. Côrtes MA, França EL, Reinaque AP, Scherer EF, HonorioFrança AC. Immunomodulation of human blood phagocytes by Strychnos pseudoquina ST. HILL adsorbed to polyethylene glycol (PEG). Polímeros. 2013;23:402-409.

31. Fagundes DL, França EL, Hara CC, Honorio-França AC. Immunomodulatory effects of poly ethylene glycol-microspheres adsorbed with cortisol on activity of colostrum phagocytes. Int $J$ Pharmacol. 2012;8:510-518.

32. Carneiro-Sampaio MM, Silva ML, Carbonare SB, et al. Breast-feeding protection against enteropathogenic Escherichia coli. Rev Microbiol. 1996;26:151-154.

33. França-Botelho AC, Honorio-França AC, França EL, Gomes MA, Costa-Cruz JM. Phagocytosis of Giardia lamblia trophozoites by human colostral leukocytes. Acta Paediatr. 2006;95:438-443.

34. Morceli G, Honorio-França AC, Fagundes DL, Calderon IM, França EL. Antioxidant effect of melatonin on the functional activity of colostral phagocytes in diabetic women. PLoS One. 2013;8:e56915.

35. Honorio-França AC, Hara CC, Ormonde JV, Nunes GT, França EL. Human colostrum melatonin exhibits a day-night variation and modulates the activity of colostral phagocytes. $J$ Appl Biomed. 2013;11:153-162.

36. Possamai MM, Honorio-França AC, Reinaque AP, França EL, Souto PC. Brazilian propolis: a natural product that improved the fungicidal activity by blood phagocytes. Bio Med Res Int. 2013;2013:1-9.

37. França-Botelho AC, Franca JL, Oliveira FC, et al. Melatonin reduces the severity of experimental amoebiasis. Parasit Vectors. 2011;4: 62-67.

38. Esposito M, Ruberto M, Pascotto A, Carotenuto M. Nutraceutical preparations in childhood migraine prophylaxis: effects on headache outcomes including disability and behaviour. Neurol Sci. 2012;33:1365-1368.

39. Carotenuto M, Esposito M. Nutraceuticals safety and efficacy in migraine without aura in a population of children affected by neurofibromatosis type I. Neurol Sci. 2013;34:1905-1909.

40. Ferrari CK. Functional foods, nutraceuticals and herbs: an approach of cell and molecular anti-ageing mechanisms. Agro Food Ind Hi Tec. 2013;8:10-13.

41. Novelli EL, Rodríguez NL, França EL, Gebra LM, Ribas BO. High dietary carbohydrate and pancreatic lesion. Braz J Med Biol Res. $1993 ; 26: 31-36$

\section{Publish your work in this journal}

Drug Design, Development and Therapy is an international, peerreviewed open-access journal that spans the spectrum of drug design and development through to clinical applications. Clinical outcomes, patient safety, and programs for the development and effective, safe, and sustained use of medicines are a feature of the journal, which

\section{Dovepress}

has also been accepted for indexing on PubMed Central. The manuscript management system is completely online and includes a very quick and fair peer-review system, which is all easy to use. Visit http://www.dovepress.com/testimonials.php to read real quotes from published authors. 